\title{
Associations between prosocial behavior, externalizing behaviors, and internalizing symptoms during adolescence: A meta-analysis
}

Laura M. Padilla-Walker

Brigham Young University, laura_walker@byu.edu

Madison k. Memmott-Elison

Hailey G. Holmgren

Follow this and additional works at: https://scholarsarchive.byu.edu/facpub

Part of the Social and Behavioral Sciences Commons

\section{Original Publication Citation}

Memmott-Elison, M. K., *Holmgren, H. G., Padilla-Walker, L. M., Hawkins, A. J. (2020, onlinefirst). Associations between prosocial behavior, externalizing behaviors, and internalizing symptoms during adolescence: A meta-analysis. Journal of Adolescence.

\section{BYU ScholarsArchive Citation}

Padilla-Walker, Laura M.; Memmott-Elison, Madison k.; and Holmgren, Hailey G., "Associations between prosocial behavior, externalizing behaviors, and internalizing symptoms during adolescence: A metaanalysis" (2020). Faculty Publications. 5499.

https://scholarsarchive.byu.edu/facpub/5499

This Peer-Reviewed Article is brought to you for free and open access by BYU ScholarsArchive. It has been accepted for inclusion in Faculty Publications by an authorized administrator of BYU ScholarsArchive. For more information, please contact ellen_amatangelo@byu.edu. 


\title{
Associations between prosocial behavior, externalizing behaviors, and internalizing symptoms during adolescence: A meta-analysis
}

\author{
Madison K. Memmott-Elison ${ }^{\mathrm{a}, *}$, Hailey G. Holmgren ${ }^{\mathrm{b}}$, Laura M. Padilla-Walker ${ }^{\mathrm{c}}$, \\ Alan J. Hawkins ${ }^{c}$ \\ ${ }^{a}$ University of Missouri, USA \\ ${ }^{\mathrm{b}}$ University of Minnesota, USA \\ ${ }^{\mathrm{c}}$ Brigham Young University, USA
}

\section{A R T I C L E I N F O}

\section{Keywords:}

Prosocial behavior

Externalizing behaviors

Internalizing symptoms

Meta-analysis

\begin{abstract}
A B S T R A C T
Introduction: The purpose of this study was to conduct a meta-analysis investigating the consistency and strength of relations between prosocial behavior, externalizing behaviors, and internalizing symptoms from preadolescence (i.e., 1-9 years) to late adolescence (i.e., 19-25 years). This study directly addresses inconsistencies and gaps in the available literature by providing the field with a detailed, synthesized description of these associations.

Method: Fifty-five studies met the inclusion criteria, containing 742 independent correlational effect sizes. Statistical information and other study information was coded and entered into Comprehensive Meta-analysis III software, which was used to analyze results.

Results: Results showed that higher levels of prosocial behavior were significantly associated with lower levels of externalizing behaviors, as expected. Additionally, more reported prosocial behavior was related to less reported internalizing symptoms. Follow-up analyses revealed specific relationships between prosocial behavior and aggression, deviant peer association, risky sexual behavior, substance use, delinquency/general externalizing behavior, depression, and general internalizing behaviors (i.e., emotional problems, negative emotionality). A variety of moderators of these associations were considered, including age and sex.

Conclusions: Findings are discussed in the context of the broader research literature, weaknesses in the field are noted, and numerous meaningful directions for future research are presented.
\end{abstract}

Prosocial behavior is defined as voluntary behavior intended to benefit others and comes in many types, such as comforting, sharing, volunteering, donating, and offering physical or emotional assistance to others, etc. (Eisenberg, Spinrad, \& Knafo-Noam, 2015). Prosocial behavior is relevant to adolescents, whose prosocial opportunities expand (Padilla-Walker, Dyer, Yorgason, Fraser, \& Coyne, 2015a), and who are especially sensitive to the quality and types of interactions they have with those in their social networks (e.g., parents and peers, Allen et al., 2003; Masten et al., 2009). In light of the developmental significance of prosocial behavior, a growing body of recent research identifies prosocial behavior as protective against myriad problematic outcomes, including but not limited to aggression (Carlo et al., 2014), academic underachievement, teen pregnancy (Allen, Philliber, Herrling, \& Kuperminc, 1997), substance use (Carlo, Crockett, Wilkinson, \& Beal, 2011), deviant peer association (Lacourse et al., 2006), depression, and anxiety (Haroz, Murray, Bolton, Betancourt, \& Bass, 2013). Though this research provides potentially valuable information to researchers and policy makers concerned with fostering adaptive adolescent outcomes and trajectories, this growing field lacks clarity

\footnotetext{
${ }^{*}$ Corresponding author. 309 Gentry Hall, Columbia, MO, 65203, USA.

E-mail addresses: madimemmott@gmail.com, mkegn2@mail.missouri.edu (M.K. Memmott-Elison).
} 
regarding the consistency and saliency of associations between prosocial behavior and problematic outcomes (i.e., both externalizing behaviors and internalizing symptoms). Therefore, the purpose of this meta-analysis was to synthesize what we know about the links between prosocial behavior and problematic outcomes, as well as identify areas that require further investigation which can guide future studies.

\section{Concern over problematic outcomes during adolescence}

Adolescence is a period when individuals encounter novel social, emotional, and cognitive stimuli, changes, and transitions (Arnett, 2000; Gilchrist, 2017; Steinberg, 2007), and accordingly establish behavioral patterns and social relationships that tend to extend into adulthood. With this in mind, participation in externalizing behaviors and experiences with internalizing symptoms during adolescence might underscore maladaptive development in adulthood, such as underachievement (Gremmen et al., 2018) or weakened or reduced social networks (Guimond, Laursen, Hartl, \& Cillessen, 2018). For instance, engagement in externalizing behaviors can be harmful because participation in such behaviors can lead to negative consequences at school (e.g., violence or drug use at school can escalate to school detention or suspension; Blomberg, 2003). Additionally, participation in minor forms of these behaviors during early adolescence sometimes leads to more serious misdeeds in middle and late adolescence, such as arrest or imprisonment (Babinski, Hartsough, \& Lambert, 1999), and those who engage in delinquent behaviors during middle adolescence have greater difficulty securing employment in adulthood (Carter, 2019). Some research even suggests that those who engage in externalizing behaviors have a younger life expectancy than their non-externalizing counterparts (Blum, 2003). Internalizing symptoms are also unhealthy because they can inhibit an adolescent's ability to interact with others (Rubin, Coplan, \& Bowker, 2009), resulting in damaged or weakened social relationships (Hymel, Rubin, Rowden, \& LeMare, 1990), and worsened internalizing symptoms (McLaughlin, Hatzenbuehler, \& Hilt, 2009) over time. Therefore, experiences with externalizing problems and internalizing symptoms during adolescence are particularly worrisome because teens are especially influenced during this time, and are at a developmental crossroads in terms of whether they will follow a positive, neutral, or negative trajectory into adulthood.

Given concerns regarding externalizing behaviors and internalizing symptoms during adolescence, it is important to note that contemporary extensions of resilience theory suggest prosocial behavior is negatively related to problem behaviors. That is, Masten (2001) argues that everyday resilience is a process that is both facilitated and augmented by simple, prudential characteristics and behaviors (e.g., prosocial behavior). Theorists and scholars have begun to focus on prosocial behavior as one possible form of resilience because it has typically moral (Eisenberg et al., 2015) or socially-adaptive (i.e., relational, Eberly \& Montemayor, 1998) foundations and lasting associations with desirable developmental outcomes, including decreased problematic outcomes. Problem Behavior Theory (PBT) compliments this perspective, postulating that engaging in positive behaviors, like prosocial behavior, enables individuals to control future urges to engage in problem behaviors by changing their general behavioral patterns and preferences (Jessor, 1987; Jessor \& Jessor, 1977). Essentially, as adolescents engage in prosocial behavior, they develop positive behavioral patterns and preferences that are compatible with further helping behavior (and other forms of adaptation), and are incompatible with problematic outcomes (Lerner, Lerner, Bowers, \& Geldhof, 2015; Masten \& Cicchetti, 2010). In other words, when adolescents engage in prosocial behavior, adaptive "developmental cascades" are initiated and flow across levels of adolescents' ecologies (Masten \& Cicchetti, 2010). Thus, day-to-day behavioral factors such as prosocial behavior may act as the "ordinary magic" that leads to everyday resilience (e.g., fewer problematic outcomes) during adolescence and beyond (Jessor, 1987; Jessor \& Jessor, 1977; Masten, 2001).

\subsection{Forms of problematic outcomes}

Externalizing behaviors. Externalizing behaviors are broadly defined as negative behaviors that occur due to a lack of regulation (Cole, Zahn-Waxler, Fox, Usher, \& Welsh, 1996). Examples include aggression, deviant peer association, hyperactivity, risky sexual behavior, substance use, and delinquency/general externalizing behavior. Each of the aforementioned externalizing behaviors will be analyzed in conjunction with prosocial behavior in the current study. Aggression refers to intentional behavior intended to harm others (Coyne, Nelson, \& Underwood, 2010), and is negatively associated with prosocial behavior (Nantel-Vivier, Pihl, Côté, \& Tremblay, 2014), as is deviant peer association (Lacourse et al., 2006), or association with individuals, peers, or friend groups who participate in delinquent behaviors (Kaplan, Johnson, \& Bailey, 1987). Hyperactivity symptoms include an excess of energy that manifests as disruptive or distracting behavior (American Psychiatric Association, 2013), and can theoretically detract from helping others if one is unable to regulate their attention toward a helpful task. Additionally, risky sexual behavior includes behaviors such as having multiple sexual partners, frequent one-night stands, and not using protection during intercourse, etc. It may be that engaging in risky sexual behaviors is incongruent with prosocial engagement because helping others is rooted in high regulatory capabilities, whereas engaging in risky sexual behavior is tied to dysregulation. Granted, there is very little empirical and theoretical support for this relation, and existent support is fairly outdated (see Biglan et al., 1990; Doljanac \& Zimmerman, 1998), so the current study tentatively focused on clarifying this association. Further, for the purpose of this meta-analysis, substance use will refer to the use of legal and illegal substances including alcohol, marijuana, cigarettes, prescription drugs, and illicit drugs. Research posits that adolescents who frequently behave prosocially are less likely to use substances than those who report lower levels of prosocial behavior (Carlo et al., 2011). Carlo et al. (2011) suggest this is because adolescents who help others are unlikely to spend time with substanceusing, underage peers because they are more attracted to peers who promote healthy behaviors. Finally, this study will also focus on delinquent/general externalizing behaviors, which include illegal behaviors such as trespassing, stealing, or other petty crimes (Padilla-Walker, Carlo, \& Nielson, 2015b), as well as general acting out, respectively. Delinquency and general externalizing 
behaviors were grouped together in the current meta-analysis because each were operationalized similarly in the included studies. Similar to explanations above, we expected prosocial behavior and delinquent/general externalizing behaviors would be negatively associated, since those who purposefully help others also theoretically avoid or an unattracted to situations where harm is caused to others (e.g., Hart, Atkins, \& Ford, 1998; Jessor, 1987; Jessor \& Jessor, 1977).

In sum, there is substantial evidence that focuses on understanding relations between prosocial and externalizing behaviors. The research presented up to this point suggests that these constructs are negatively related to one another, though it is worth noting that the strength of these relations tends to vary. For instance, aggression is more consistently negatively related to prosocial behavior than other externalizing behaviors such as hyperactivity or risky sexual behavior. That being said, a contradictory line of research exists, which claims that prosocial behavior has weak (at best), neutral, or even positive links to externalizing behaviors (see Gerardy, Mounts, Luckner, \& Valentiner, 2015; Gill \& Calkins, 2003; Hawley, 2003, 2014; Kokko, Tremblay, Lacourse, Nagin, \& Vitaro, 2006; Krueger, Hicks, \& McGue, 2001). This conflicting research suggests that a portion of children and adolescents (Kokko et al., 2006) concurrently demonstrate moderate to high levels of helpful and aggressive behavior in order to achieve social goals (Hawley, 2003). From this viewpoint, prosocial and externalizing behaviors (i.e., aggression) are viewed as behavioral strategies that youth advantageously employ based on social context and perceived need (Hawley, 2003; Kokko et al., 2006). Although a subgroup of children and adolescents may consistently engage in both prosocial and externalizing behaviors, research indicates that youth engage in more cohesive behavioral patterns over time (Kokko et al., 2006), so it is likely that prosocial and externalizing behaviors become less compatible by mid-adolescence (see Carlo et al., 2014; Padilla-Walker, Memmott-Elison, \& Coyne, 2017). Given these inconsistent findings, the results of the current study will be especially salient in clarifying associations between prosocial and externalizing behaviors, and pointing toward meaningful directions for future research and the development of adolescent-specific resilience models.

Internalizing symptoms. There is additional limited research that suggests prosocial behavior is negatively related to internalizing symptoms, which are internal (e.g., cognitive, affective) difficulties associated with over-regulation (Cole et al., 1996). Forms of internalizing symptoms focused on in the current study include depression, (low) self-esteem, self-harm/suicide ideation, and general internalizing symptoms (i.e., general cognitive and affective difficulties). Studies that investigate associations between prosocial behavior and these internalizing symptoms typically rely on conceptual explanations extended from PBT (Jessor, 1987; Jessor \& Jessor, 1977) or other work in the moral domain (e.g., Hart et al., 1998). These scholars reason that adolescents who are able to optimally regulate themselves when engaging in prosocial behavior are not likely to over-regulate themselves in other situations to the extent that internalizing symptoms incur. Though there is some merit to this argument, there are also conceptual pitfall$\mathrm{s}$-primarily that internalizing symptoms are not behaviors, and therefore are likely not as strongly negatively related to prosocial behavior as other problematic outcomes like externalizing behaviors.

With this conceptual limitation in mind, it is still worth investigating the consistency of relations between prosocial behavior and internalizing symptoms because of pragmatic implications that have quickly gained the interest of scholars, educators, field workers, and policy makers. Granted, results across extant studies are currently unreliable. For example, some research shows that helping others is negatively related to depression (during adolescence, Nantel-Vivier et al., 2014; during adulthood, Wright, 2015), while one study argues that prosocial behavior is only significantly (negatively) related to depression in youth from disadvantaged socioeconomic backgrounds (Nantel-Vivier et al., 2014). Another study revealed no association between prosocial behavior and depression (Padilla-Walker et al., 2015b), while Fujiwara (2009) reported that prosocial behavior (in the form of donating money) was associated with increased depression (in a sample of adults). Research on the association between prosocial behavior and additional internalizing symptoms (i.e., low self-esteem, self-harm/suicide ideation, and general internalizing symptoms) are similarly inconsistent, if not more so. The current study will address these discrepancies by synthesizing research that focuses on the association between prosocial behavior and internalizing symptoms, and by exploring moderators of the strength and nature of these associations. We hope to build on research that preliminarily suggests that prosocial behavior is most consistently related to depression compared to other forms of internalizing symptoms.

\section{Previous meta-analyses}

To our knowledge, two meta-analyses exist that examine relations between prosocial behavior and problematic outcomes. The first was conducted by Ciocanel, Power, Eriksen, and Gillings (2016) and focused on the association between positive youth development intervention programs and adolescent risk behaviors. Researchers found that positive youth intervention programs had no effect on risky sexual behavior, problem behavior, or prosocial behavior. A second meta-analysis investigated the effects of formal volunteering on the physical and mental health of older adults in cohort and experimental studies, concluding that formal volunteering was not significantly associated with internalizing symptoms like depression, self-reported health, and self-esteem (Jenkinson et al., 2013).

Although these studies contributed to the literature focusing on the link between prosocial behavior and problematic outcomes, our study is unique and moves the field forward in a more meaningful way, in that it more broadly defines prosocial behavior by including a diverse range of types of helping behavior (with the exception of formal opportunities to volunteer, which was the sole focus of both previously discussed meta-analyses). In addition, the current meta-analysis is requisite as neither of the previous metaanalyses analyzed such a wide variety of externalizing behaviors and internalizing symptoms in relation to prosocial behavior. Thus, the current study is warranted in relation to previous meta-analytic work and will contribute in unique and noteworthy ways to the current research literature. 


\section{Potential moderators}

The goal of this meta-analysis is to better understand the associations between prosocial behavior and various externalizing behaviors and internalizing symptoms, respectively, while taking into account conceptually-relevant moderating factors that may strengthen or weaken these associations. In the current study, we attempt to test the following moderating factors: age, sex, race, family income, parental education, type of helping behavior, publication status, and study design.

Sample demographics. A large body of research describes the relationships between demographic characteristics and prosocial behavior and problematic outcomes, respectively. However, the vast majority of this research focuses on whether demographic information affects initial levels of prosocial behaviors and problematic outcomes, but does not aim to assess whether demographic factors moderate relations between variables. Thus, this study seeks to extend past work by analyzing age, sex, race, family income, and parental education as moderators. In order to assess whether associations between prosocial behavior and problematic outcomes were unique to the period of adolescence, we chose also to include studies conducted on children (ages 1-9 years). Past research is lacking in terms of longitudinal work that spans from childhood to adolescence (ages 10-25 years), though some research suggests adolescents engage in more prosocial behavior than children (Eisenberg, Miller, Shell, McNalley, \& Shea, 1991), and that youth engage in or encounter problematic outcomes at an increasing rate from childhood to adolescence (Williams et al., 2009). In terms of biological sex, research consistently reveals that girls tend to report higher levels of prosocial behavior (Zimmer-Gembeck, Geiger, \& Crick, 2005) and internalizing symptoms than boys, and boys tend to participate in more externalizing behaviors than girls (Leadbeater, Kuperminc, Blatt, \& Hertzog, 1999). Past research also indicates that racial/ethnic makeup, family income, and parental education are linked to prosocial behavior in past research, where individuals of European descent, who come from high-earning families, and have more highly educated parents tend to engage in more prosocial acts (Department for Communities and Local Government, 2009; Piff, Kraus, Côté, Cheng, \& Keltner, 2010). These individuals are also less likely to engage in externalizing behavior or experience internalizing symptoms (Kalff et al., 2001; McLoyd, 1997). Granted, studies focusing on these demographic factors are uncommon and are also generally inconsistent, and therefore unclear. As such, this study will help increase understanding of how individuals' traits and lived experiences moderate associations between prosocial behavior and problematic outcomes during adolescence.

Measurement and study characteristics. In addition to demographic factors, past meta-analyses and relevant research indicate that study characteristics tend to affect links between constructs of interest. For instance, Padilla Walker and Carlo (2014) explained that distinctions in prosocial behavior are often uncovered as researchers study specific types of helping behaviors. For instance, Carlo, Hausmann, Christiansen, and Randall (2003) elaborated on multiple types of prosocial behavior that are enacted based on differing motivations, such as altruistic behavior and emotional prosocial behavior. Additionally, Nielson, Padilla-Walker, and Holmes (2017) developed and validated a multidimensional measure for prosocial behavior including defending, emotional support, inclusion, physical helping, and sharing. Therefore, it is important for us in the current study to investigate whether the type of prosocial behavior being studied affects links between helping and problematic outcomes. As such, we will examine whether associations between prosocial behavior and problematic outcomes vary based on the type of prosocial behavior enacted (i.e., prosocial behavior, volunteering/community service, assisting, altruism). In addition, past studies suggest that peer-reviewed or published studies are more likely to report significant findings compared to non-peer reviewed or unpublished studies (Lipsey \& Wilson, 2001) so publication status also will be analyzed as a moderator. Lastly, scholars should take into account whether included studies employ cross-sectional or longitudinal approaches to studying prosocial and problem behaviors (i.e., study design), as design elements likely impact these associations.

\section{Method}

\subsection{Inclusion and exclusion criteria}

Studies were retained for analysis based on the following inclusion/exclusion criteria. First, the studies had to contain a measure of prosocial behavior, defined as voluntary behavior intended to benefit another person (Eisenberg et al., 2015). This included helpful behaviors such as prosocial behavior, allocentric tendencies, volunteering/community service, assisting, and altruism. Second, studies were included if they also measured a form of either externalizing behaviors (e.g., aggression, deviant peer association, hyperactivity, risky sexual behavior, substance use, and delinquency/general externalizing behavior) or internalizing symptoms (e.g., depression, low self-esteem, self-harming behavior/suicide ideation, and general internalizing symptoms). Third, experimental studies involving intervention programs or treatments, or focusing on populations older than adolescents (e.g., middle aged and older adults) were excluded from analyses. Fourth, studies had to provide appropriate and adequate statistical information to calculate an effect size. Finally, only studies that were written in English (or could be translated into English) were included.

\subsection{Literature search procedures}

A three-step process was utilized to obtain relevant articles. First, from September-December 2018, we conducted a thorough literature search using PsycINFO, Academic Search Premier (EBSCO), and PROquest (for relevant dissertations and theses). There were no restrictions on the time period, geography, or culture in which studies were conducted. Based on the prosocial literature, the following terms were searched for throughout the title, abstract, keywords, and entire text of each article: "helping behaviors," "altruism," "prosocial behavior," "volunteering," "donating," “assistance," "charitable behavior," "allocentrism," and "internaliz "” 


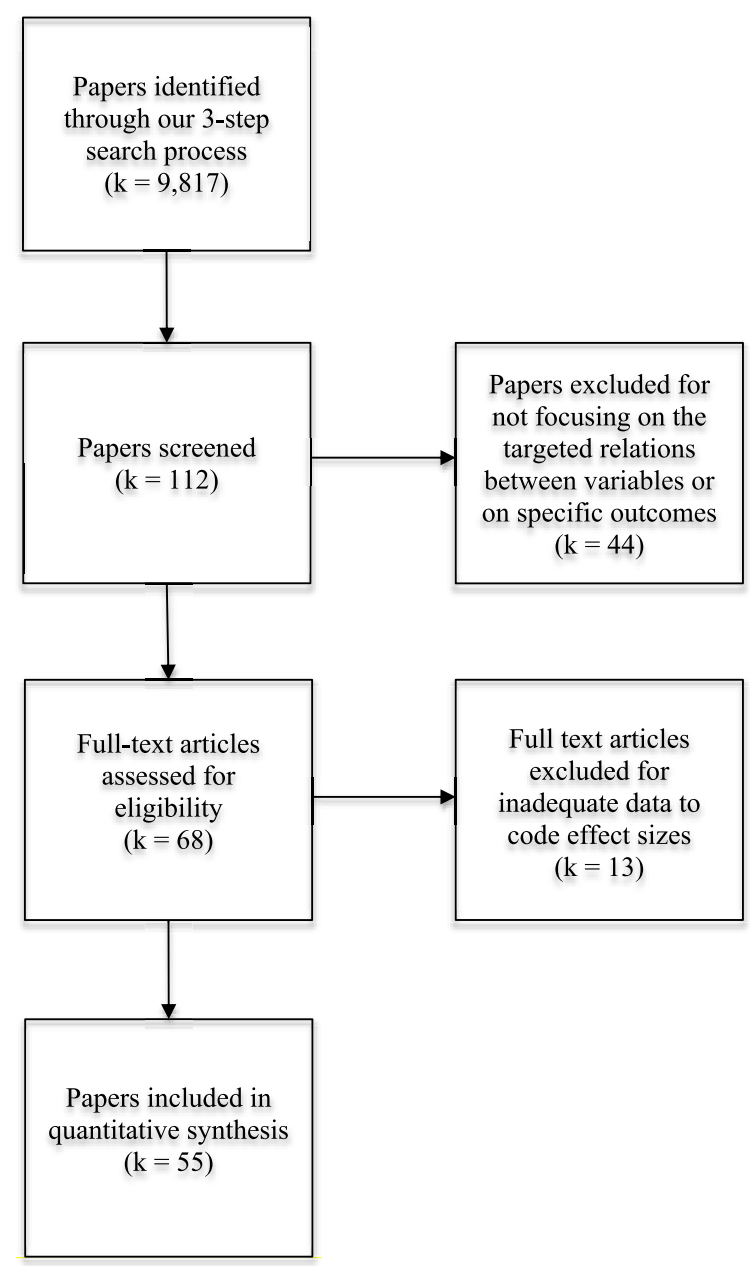

Fig. 1. Flowchart of including/excluding studies.

and "externaliz"“, not "intervention"” or "treatment". Second, the references cited in existing meta-analyses noted above (Ciocanel et al., 2016; Jenkinson et al., 2013) were examined for applicability to the current study.

Fig. 1 provides a flowchart of inclusion/exclusion decisions. Our initial search resulted in 9817 articles. A superficial review of titles and abstracts included assessing whether the 9817 identified articles applied to our meta-analysis based on study information (e.g., assessed prosocial behavior, analyzed the relations between prosocial behavior and either externalizing behaviors or internalizing symptoms, etc.). This superficial review focused attention on just 100 studies deemed potentially relevant to the current study. The third step of our literature search process included implementing additional search techniques such as (a) searching through review articles on similar topics; (b) searching for articles by authors who had more than one study included in our search; and (c) emailing prominent authors in the field, asking for access to unpublished data and any research that was currently in preparation, in press, or had been presented at conferences. These efforts yielded an additional four, two, and six studies, respectively (i.e., an additional 12 studies total), leaving us with a total of 112 potentially relevant studies.

We conducted more thorough reviews of these 112 studies, resulting in exclusion of 44 additional articles that did not meet the inclusion/exclusion criteria, leaving 68 potential papers. Primary reasons for excluding those 44 studies included the following: (a) relations between prosocial behavior and problematic outcomes relevant to our study were not directly hypothesized or tested in the study; (b) the study measured a problematic outcome that was not relevant to the current meta-analysis; (c) the study included an intervention component; and (d) the study focused on individuals outside of our target age range (i.e., middle-aged and older adults). Additionally, when coding for effect sizes, there were 13 studies excluded because they did not include the necessary statistical information. In these cases, we contacted the study authors two times through email for the needed statistical information, but none responded with relevant information. Accordingly, we were left with 55 relevant studies, which were included in this meta-analysis. See Table 1 for a description of each included study. 


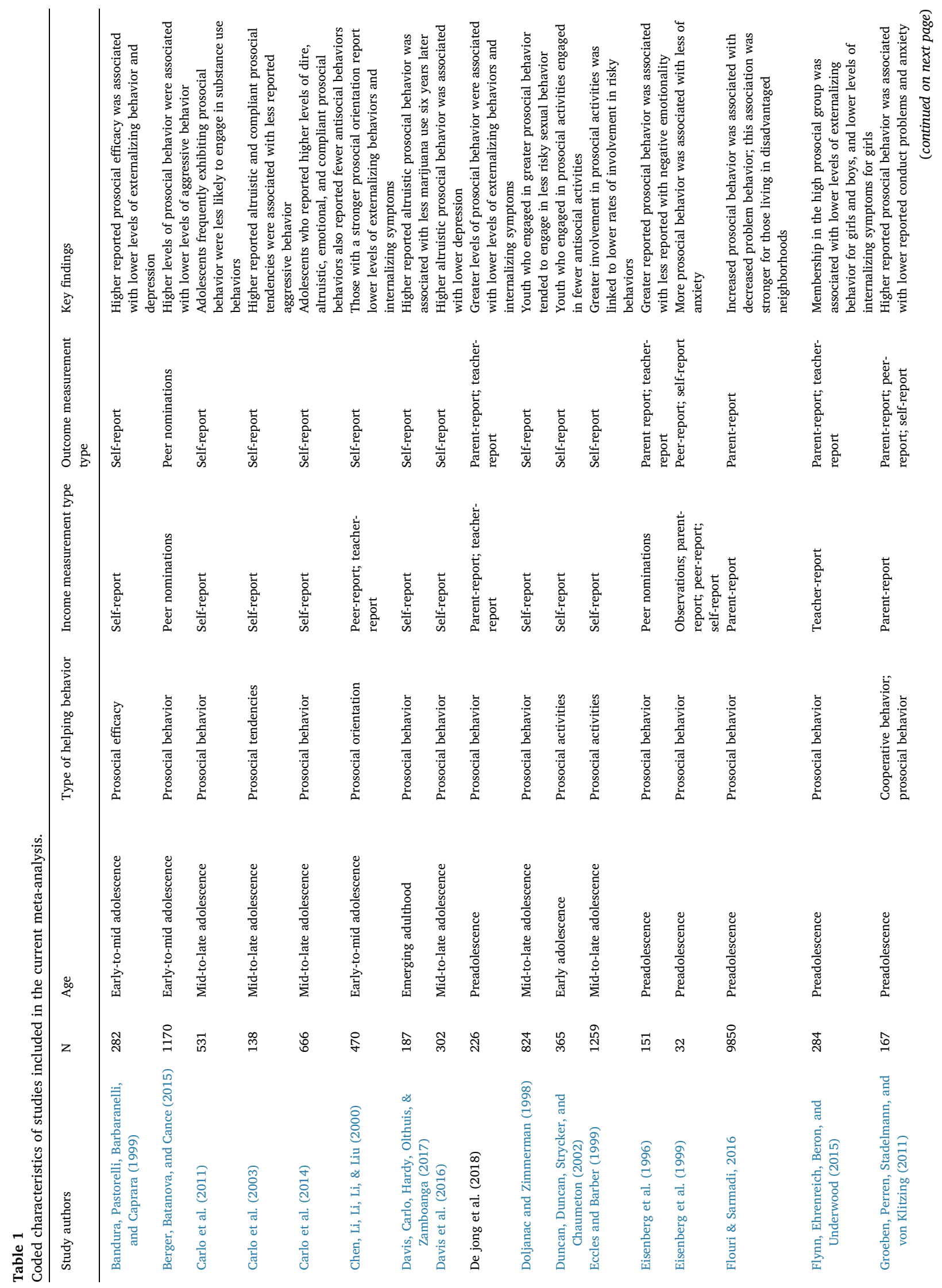




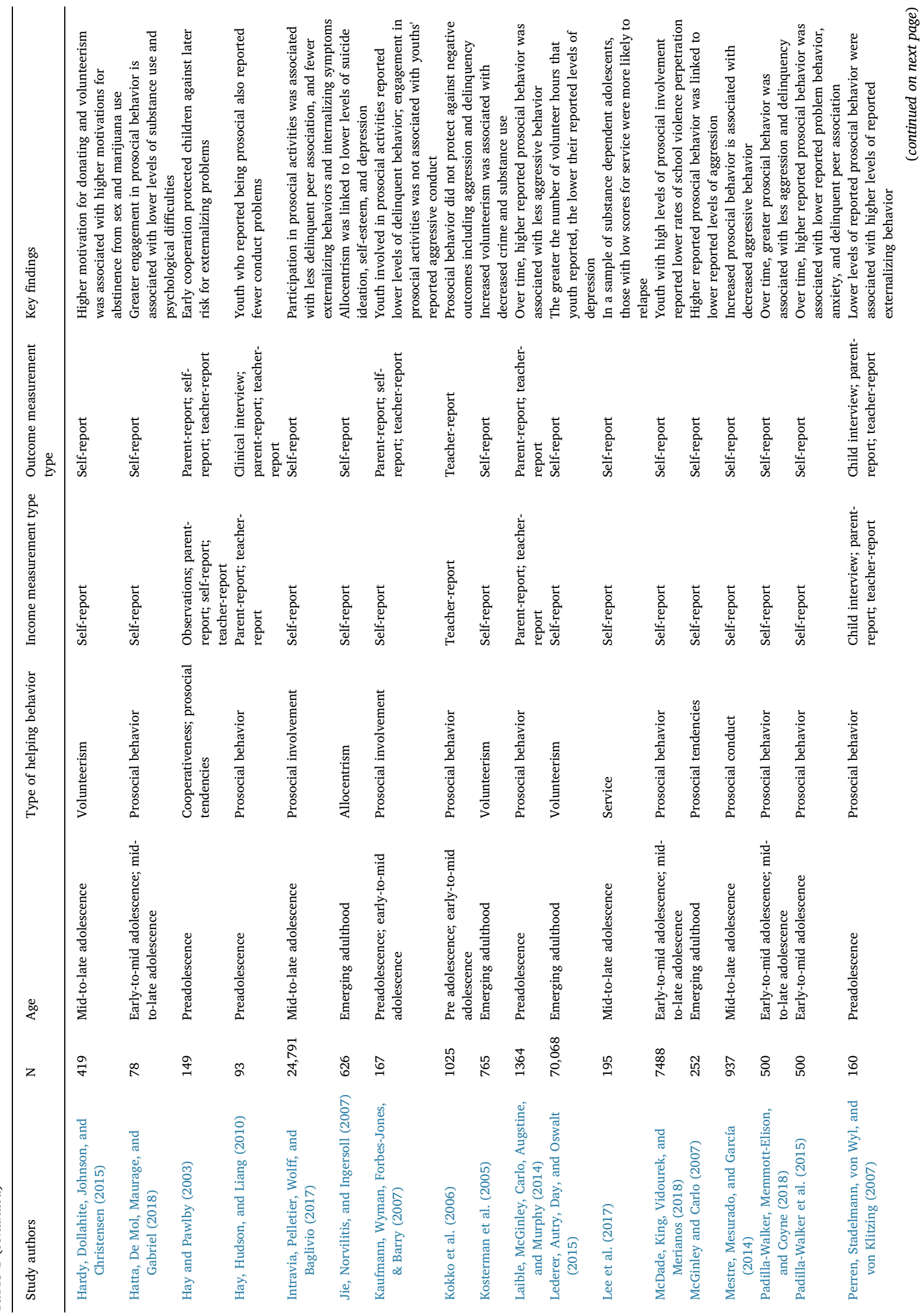




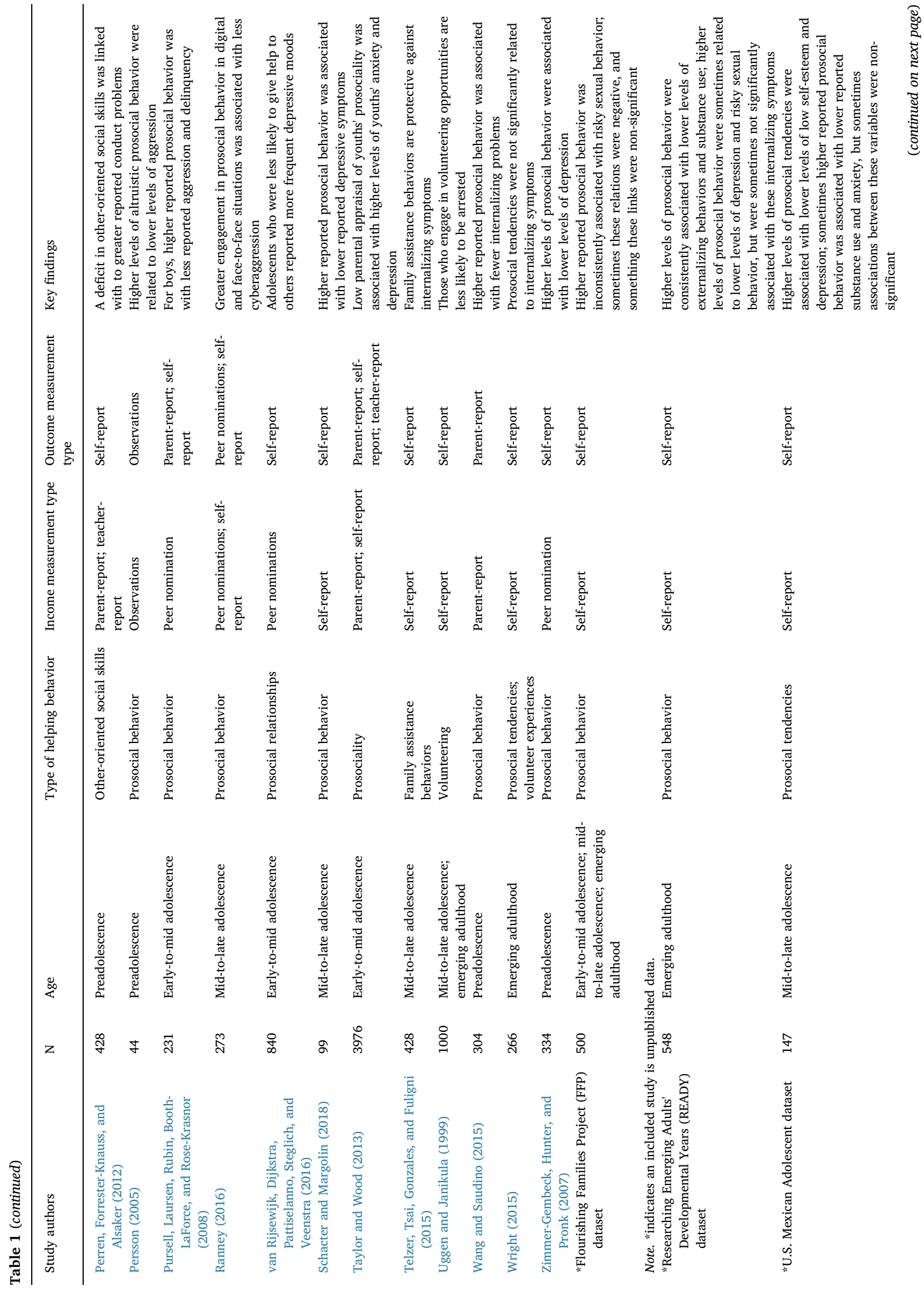




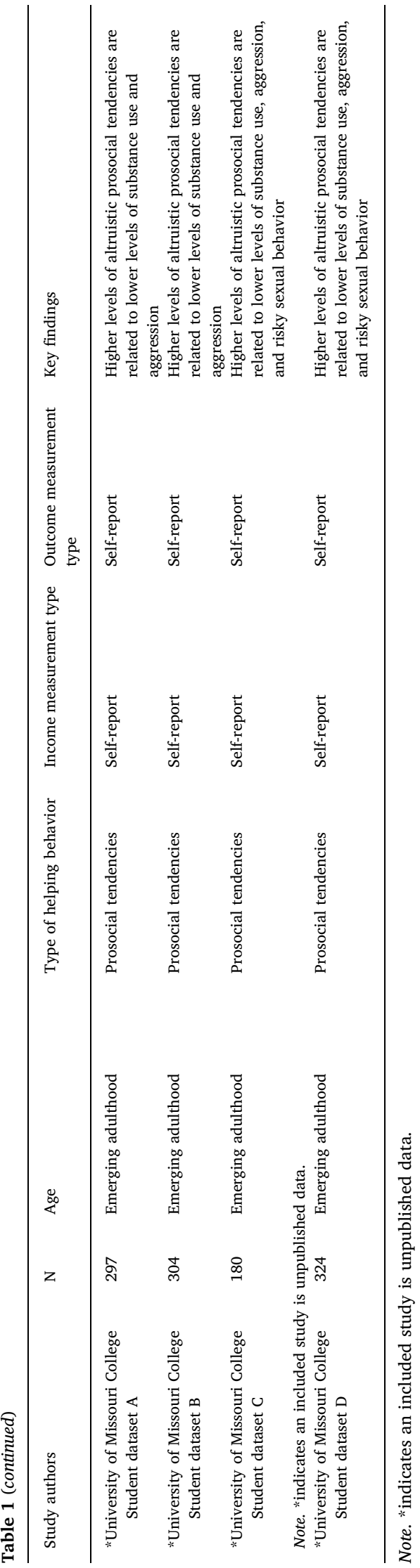




\subsection{Moderators}

A number of potential moderators were coded for each study.

Age. The age of participants was coded as follows: (a) Preadolescence (age 1-9 years), (b) Early adolescence (age 10-13 years), (c) Middle adolescence (14-18 years), and (d) Emerging adulthood (19-25 years). In the case of longitudinal studies, the age of participants in the study was coded as the age of participants at the last measurement point.

Sex. Sex of participant was noted only when a study provided separate statistics for (a) girls and (b) boys; if not, the study was coded as (c) "both".

Ethnicity/race. The ethno-racial diversity of the sample was determined from each article and included: (a) Predominantly NonEuropean American, (b) Predominantly European American, (c) Multiple, or (d) Not Reported. The code for multiple was used when no one group comprised $50 \%$ or more of the sample.

Income. Income of participants was coded as (a) Low (\$0-\$40,000/year), (b) Moderate $(\$ 40,001-\$ 80,000 /$ year), (c) High (\$80,001 + /year), and (d) Not Reported.

Parental education. Parental education was coded as one of three categories: (a) High school education (including obtaining a GED) or less, (b) Some college or more, and (c) Not Reported.

Family structure. Family structure was coded as: (a) 2-Parent Family and (c) Not Reported. We discovered no studies that focused on single-parent families.

Type of helping behavior. For type of helping behavior, studies were coded as measuring one of the following: (a) Prosocial Behavior or (b) Volunteering/community service, (c) Assisting, (d) Altruism, and (e) Multiple (i.e., more than one type of prosocial behavior was measured).

Publications status. In terms of publication status, studies were either coded as (a) Peer-reviewed or Published (i.e., journal articles, book chapters) or (b) Non-peer-reviewed or Unpublished (i.e., articles in preparation, conference presentations, unpublished data).

Study design. Studies were coded as employing either a (a) Cross-sectional design or a (b) Longitudinal design.

\subsection{Computation of effect sizes}

Comprehensive Meta-analysis III (CMA) software was used to analyze the results. Each piece of relevant statistical information (e.g., regression coefficients, bivariate correlations, etc.) that was coded for each included study was entered into CMA, and was converted to a correlation coefficient. Accordingly, each correlation coefficient underwent a Fisher z-transformation to normalize its distribution (Silver \& Dunlap, 1987). All $d$ metric effect sizes were converted to the $r$ metric. The average effect size for each outcome was obtained and transformed back into Pearson's $r$ for interpretation. The pooled estimate of $r$ is denoted as $r_{+}$. Effect sizes were coded positive when the direction of the effect was as expected (e.g., positive when prosocial behavior was associated with decreased problematic outcomes).

Many of our studies reported multiple effect sizes relevant to our meta-analysis (e.g., separate correlations for externalizing behaviors and internalizing symptoms). The effect-size estimates were combined and averaged within each study to provide an overall effect size estimate. This approach maintains as much of the data as possible without violating the independence assumption underlying the validity of meta-analytic procedures. Analyses were conducted using a random effects model that assumes a distribution of effects rather than one true effect. That is, we assume that the true effect size can vary from one study to another based on both random and systematic variance. A summary effect size represents the mean of the distribution of effect sizes.

Finally, analyses were conducted to explore the possibility of publication bias (also called selection bias) or the idea that studies with nonsignificant results are less likely to be published than studies with significant results. To examine the potential of selection bias, we employed the Duval and Tweedie (2000) trim and fill procedure.

Transformed data. For one included study, we had to transform the relevant statistics into log-risk ratios. Subsequently, we tested whether including this study with a transformed effect size biased or changed the overall effect. The difference was minimal, so this study with transformed effect sizes was retained in all analyses.

\section{Analysis plan}

First, we computed the overall or summary effect between prosocial behavior and problematic outcomes (i.e., externalizing behavior and internalizing symptoms combined). Second, we examined the associations separately for (a) prosocial behavior and overall externalizing behaviors, and (b) overall internalizing symptoms. Third, we analyzed relations between prosocial behavior and each problematic outcome individually (when enough studies on each outcome were included to make this possible). Fourth, Duval and Tweedie's trim and fill procedure was employed and funnel plots were examined to assess potential missing-study bias present in effect size estimates. Finally, we tested for moderation in the links between prosocial behavior and externalizing behavior and internalizing symptoms, respectively, when substantial systematic heterogeneity was present.

\section{Findings}

The current meta-analysis consisted of 55 studies. Collectively, there were 134,667 participants, ranging in age from preadolescence to emerging adulthood. Of these, 42 studies examined the effect of prosocial behavior on externalizing behavior and 26 
examined the effect of prosocial behavior on internalizing symptoms. From these studies, we coded 742 independent correlational effect sizes for analyses. Below, we report overall effect sizes for problematic outcomes combined. Then, where possible, we report effect sizes for specific types of externalizing behaviors and internalizing symptoms. Moderator analyses, including age, sex, race, family income, parental education, type of helping behavior, publication status, and study design were interpreted only when at least four studies were included in each moderator category (to minimize capitalizing on chance findings). Of course, many studies did not report all of the moderator variables we were interested in, so moderator analyses were limited by this fact.

\subsection{Overall effect sizes}

Overall, findings revealed a significant positive effect between prosocial behavior and problematic outcomes $\left(r_{+}=.17,95 \% \mathrm{CI}\right.$ [.12-.22], $\left.p<.001, k=55 ; I^{2}=96.97 ; \tau^{2}=.03\right)$. This means that higher reported levels of prosocial behavior were significantly associated with lower reported levels of problematic outcomes. Follow-up analyses revealed engagement in more prosocial behavior was significantly associated with less externalizing behavior, as expected $\left(r_{+}=.20,95 \% \mathrm{CI}[.15-.25], p<.001, k=42 ; I^{2}=94.12\right.$; $\left.\tau^{2}=.02\right)$. And prosocial behavior was weakly, positively associated with internalizing symptoms $\left(r_{+}=.08\right.$, 95\% CI [.04-.12], $p<.001, k=26 ; I^{2}=87.52 ; \tau^{2}=.01$ ).

In terms of externalizing behaviors, higher levels of prosocial behavior were significantly related to lower levels of aggression $\left(r_{+}\right.$ $=.23,95 \%$ CI [.13-.33], $\left.p<.001, k=19 ; I^{2}=96.45 ; \tau^{2}=.05\right)$, deviant peer association $\left(r_{+}=.12,95 \%\right.$ CI [.04-.20], $p=.004$, $\left.k=5 ; I^{2}=84.64 ; \tau^{2}=.01\right)$, risky sexual behavior $\left(r_{+}=.15,95 \%\right.$ CI $\left.[.03-.26], p=.016, k=6 ; I^{2}=89.77 ; \tau^{2}=.02\right)$, substance use $\left(r_{+}=.11,95 \%\right.$ CI [.06-.16], $\left.p<.001, k=16 ; I^{2}=83.36 ; \tau^{2}=.01\right)$, and delinquency/general externalizing behavior $\left(r_{+}=.17\right.$, 95\% CI [.10-.24], $\left.p<.001, k=19 ; I^{2}=94.46 ; \tau^{2}=.02\right)$. Too few studies included effect sizes for hyperactivity to be analyzed individually.

Concerning internalizing symptoms, increased prosocial behavior was significantly related to decreased depression $\left(r_{+}=.10\right.$, 95\% CI [.03-.17], $\left.p=.006, k=14 ; I^{2}=90.57 ; \tau^{2}=.016\right)$ and general internalizing symptoms $\left(r_{+}=.07,95 \%\right.$ CI [.01-.12], $\left.p=.019, k=12 ; I^{2}=59.93 ; \tau^{2}=.004\right)$. However, prosocial behavior was not significantly associated with anxiety $\left(r_{+}=.05,95 \%\right.$ CI [-.08-.17], $\left.p=.458, k=7 ; I^{2}=77.83 ; \tau^{2}=.02\right)$. Again, studies that included specific effect sizes for low self-esteem and suicide ideation were too few to analyze individually.

\subsection{Missing-study bias}

Even in a meta-analysis with as many studies as we have identified here, there still is a risk that effect sizes are inflated due to publication or missing-study bias. Accordingly, we employed a Duval and Tweedie Trim and Fill analysis and also conducted a cumulative meta-analysis after sorting studies by sample size (as recommended by Borenstein, Hedges, Higgins, \& Rothstein, 2011) to look for evidence of bias. These analyses were conducted using the combined problematic outcomes to maximize statistical power. The Duval and Tweedie Trim and Fill analysis suggested three studies to the right of the mean effect size be trimmed, but the adjusted effect size was essentially the same as the unadjusted effect size $(r+=.19)$. And when a cumulative meta-analysis was conducted and the accompanying cumulative forest plot was analyzed, the effect size stabilized prior to the inclusion of studies with smaller sample sizes, and did not shift thereafter. Thus, there is little evidence for missing-study bias in the current study.

\subsection{Moderator analyses}

Externalizing behaviors. First, simple moderator analyses were conducted on the association between prosocial behavior and all externalizing behaviors (i.e., aggression, deviant peer association, risky sexual behavior, substance use, and delinquency/general externalizing behavior). A heterogeneity test provided evidence of systematic variation $(Q(41)=696.68, p<.001)$, suggesting the value of exploring potential moderators. Results revealed associations between prosocial and externalizing behaviors were strongest for studies with samples of both females and males $(k=35)$, compared to samples of only females $(k=4)$. (We did not compare studies with these samples to the only-male samples because there were only 3). Further, the association between prosocial and externalizing behavior was weaker in studies conducted in North America, compared to studies conducted in Europe. (We were unable to include studies outside of North America and Europe in our moderator analyses because there were only 3.) We did not perform moderator analyses by family structure because most studies did not report family structure. Type of prosocial behavior also affected associations between prosocial and externalizing behavior; that is, prosocial behavior was more strongly related to externalizing behaviors than specific forms of helping behaviors, particularly volunteering, community service, altruism, or combinations of these types. Finally, there was no evidence that age, ethnicity/race, income, parental education, publication status, or study design affected the strength of associations between prosocial and externalizing behavior (See Table 2 for all coefficients related to moderator analyses between prosocial and externalizing behaviors.).

Internalizing symptoms. Second, moderator analyses were conducted on the association between prosocial behavior and all internalizing symptoms (i.e., depression and general internalizing symptoms). A heterogeneity test provided evidence of systematic variation $(Q(23)=185.58, p<.001)$, suggesting the potential value of moderator analyses. We found that the association between prosocial behavior and internalizing symptoms was strongest for early adolescents, followed by middle adolescents, and that prosocial behavior and internalizing symptoms were not significantly associated in samples of emerging adults. (There were not enough studies that included preadolescents to be analyzed.) Additionally, prosocial behavior was more strongly related to internalizing symptoms in samples gathered from Europe $(k=7)$ than from North America $(k=14)$. (Again, we were unable to compare the 
Table 2

Results of moderation analyses for externalizing behavior outcomes.

\begin{tabular}{|c|c|c|c|}
\hline \multirow[t]{2}{*}{ Moderator categories } & \multicolumn{3}{|c|}{ Analysis of moderators on externalizing behaviors } \\
\hline & QBetween & $\underline{\mathrm{d}}$ & $\underline{\mathrm{k}}$ \\
\hline Age & 5.13 & & \\
\hline Preadolescence (1-9) & & .25 & 5 \\
\hline Early adolescence (10-13) & & .27 & 12 \\
\hline Middle adolescence (14-18) & & .16 & 14 \\
\hline Late adolescence (18-25) & & .14 & 11 \\
\hline Sex & $15.23^{* * *}$ & & \\
\hline Combined & & $.22^{* * *}$ & 35 \\
\hline Female only & & -.01 & 4 \\
\hline Male only & & .22 & 3 \\
\hline Ethnicity/race & 1.55 & & \\
\hline Ethnic/racial minority & & $.13^{* * *}$ & 8 \\
\hline White & & $.22^{*}$ & 25 \\
\hline Mixed & & $.22^{* * *}$ & 6 \\
\hline Not reported & & $.18^{\dagger}$ & 3 \\
\hline Income & $7.56^{\dagger}$ & & \\
\hline Low & & .10 & 5 \\
\hline Moderate & & .29 & 9 \\
\hline High & & .11 & 4 \\
\hline Not reported & & .19 & 24 \\
\hline Parental education & 4.38 & & \\
\hline High school diploma, equivalent, or less & & $.15^{* * *}$ & 9 \\
\hline Some college or more & & $.23^{* * *}$ & 12 \\
\hline Not reported & & $.20^{* * *}$ & 21 \\
\hline Family structure & $4.76^{*}$ & & \\
\hline 2-parent & & $.31^{* * *}$ & 11 \\
\hline Not reported & & $.16^{* * *}$ & 31 \\
\hline Type of helping behavior & $15.56^{* *}$ & & \\
\hline Prosocial behavior & & $.23^{* * *}$ & 26 \\
\hline Volunteering/community service & & $.12^{* * *}$ & 5 \\
\hline Assisting & & -.01 & 1 \\
\hline Altruism & & $.18^{* * *}$ & 4 \\
\hline Multiple & & $.20^{* *}$ & 6 \\
\hline Publication status & .78 & & \\
\hline Published & & $.21^{* * *}$ & 33 \\
\hline Unpublished & & $.17^{* * *}$ & 9 \\
\hline Study design & $3.19^{\dagger}$ & & \\
\hline Correlational & & $.16^{* * *}$ & 27 \\
\hline Longitudinal & & $.27^{* * *}$ & 15 \\
\hline
\end{tabular}

Note. ${ }^{\dagger} p<.08 * p<.05,{ }^{* *} p<.01,{ }^{* * *} p<.001$.

studies from North America and Europe with those from elsewhere due to a limited number of studies.) Analyses yielded no evidence that sex, ethnicity/race, income, parental education, family structure, and study design moderated the relationship between prosocial behavior and internalizing symptoms. Additionally, the results of moderator analyses by type of helping behavior and publication status could not be interpreted because too few studies existed in each of the moderator cells. (See Table 3 for all coefficients related to moderator analyses between prosocial behavior and internalizing symptoms).

\section{Discussion}

This study employed a meta-analytic approach to investigate associations between prosocial behavior and problematic outcomes (i.e., externalizing behavior and internalizing symptoms) in the hope of clarifying currently inconsistent findings in the research literature. Results indicated prosocial behavior is significantly negatively associated with overall externalizing behaviors and internalizing symptoms. In-depth analyses revealed higher levels of prosocial behavior are moderately related to lower levels of aggression, delinquency, risky sexual behavior, substance use, and general externalizing behavior; and more prosocial behavior is weakly related to less depression and general internalizing symptoms. Type of prosocial behavior moderated associations between prosocial behavior and problematic outcomes.

\subsection{Theoretical implications}

In line with PBT and theories of resilience (Jessor, 1987; Jessor \& Jessor, 1977; Lerner et al., 2015; Masten, 2001) and related research (e.g., Carlo et al., 2011; Haroz et al., 2013), we found that higher levels of prosocial behavior were related to lower levels of both externalizing behaviors and internalizing symptoms. Thus, this study indicates that more reported engagement in helpful, other- 
Table 3

Results of moderation analyses for internalizing symptoms outcomes.

\begin{tabular}{|c|c|c|c|}
\hline \multirow[t]{2}{*}{ Moderator categories } & \multicolumn{3}{|c|}{ Analysis of moderators on internalizing symptoms } \\
\hline & QBetween & $\underline{\mathrm{d}}$ & $\underline{\mathrm{k}}$ \\
\hline Age & $9.50 *$ & & \\
\hline Preadolescence (1-9) & & $.11^{\dagger}$ & 3 \\
\hline Early adolescence (10-13) & & $.17^{* * * *}$ & 7 \\
\hline Middle adolescence (14-18) & & $.07 *$ & 9 \\
\hline Late adolescence (18-25) & & .02 & 5 \\
\hline Sex & 2.01 & & \\
\hline Combined & & $.09 * * *$ & 20 \\
\hline Female only & & $.21^{\dagger}$ & 2 \\
\hline Male only & & .003 & 2 \\
\hline Ethnicity/race & 5.22 & & \\
\hline Ethnic/racial minority & & $.12^{* * *}$ & 12 \\
\hline White & & $.06^{\dagger}$ & 5 \\
\hline Mixed & & .07 & 4 \\
\hline Not reported & & $.22 * *$ & 3 \\
\hline Income & 3.50 & & \\
\hline Low & & .003 & 1 \\
\hline Moderate & & .14 & 6 \\
\hline High & & - & 0 \\
\hline Not reported & & $.09 * * *$ & 17 \\
\hline Parental education & .35 & & \\
\hline High school diploma or less & & $.12 * *$ & 6 \\
\hline Some college, Bachelor's degree, or post-Bachelor's degree & & $.09 *$ & 5 \\
\hline Not reported & & $.09 * *$ & 13 \\
\hline Family structure & .11 & & \\
\hline 2-parent & & $.09 *$ & 8 \\
\hline Not reported & & $.10^{* * * *}$ & 16 \\
\hline Type of helping behavior & $12.59^{*}$ & & \\
\hline Prosocial behavior & & $.13^{* * *}$ & 16 \\
\hline Allocentric tendencies & & .03 & 1 \\
\hline Volunteering/community service & & .09 & 3 \\
\hline Assisting & & -.03 & 1 \\
\hline Altruism & & - & 0 \\
\hline Multiple & & $.13^{* *}$ & 3 \\
\hline Publication status & 1.26 & & \\
\hline Published & & $.10 * * *$ & 21 \\
\hline Unpublished & & $.04 * * *$ & 3 \\
\hline Study design & 1.20 & & \\
\hline Correlational & & $.07 * *$ & 14 \\
\hline Longitudinal & & $.12 * *$ & 10 \\
\hline
\end{tabular}

Note. ${ }^{*} p<.08,{ }^{*} p<.05,{ }^{* *} p<.01,{ }^{* * *} p<.001$.

oriented behaviors is related to fewer reported problematic outcomes during the adolescent period. Perhaps helping others creates positive behavioral patterns that take the place of or are counter to engagement in or experiences with problematic outcomes (Jessor, 1987; Jessor \& Jessor, 1977). It may also be that helping others enables the development of a moral self, which becomes counterintuitive to experience with problematic outcomes, especially externalizing behaviors (Aquino \& Reed, 2002; Hart et al., 1998). Additional theoretical variations and tenets should be explored, especially regarding associations between prosocial behaviors and internalizing symptoms. It is important to mention that this study did not consider possible explanatory mechanisms (i.e., mediators) in associations between prosocial behavior and problematic outcomes largely due to inconsistent or nonexistent research on this topic. We urge scholars to focus future work on investigating why or how prosocial behavior is negatively related to problematic outcomes in order to expand current theoretical frameworks and increase the field's understanding of these associations. This is a pressing next step for researchers.

\subsection{Differential associations with externalizing behaviors and internalizing symptoms}

Prosocial behavior was moderately associated with overall externalizing behavior (i.e., $r+=.20$ ) and weakly to overall internalizing symptoms (i.e., $r+=.08$ ). In terms of specific problematic outcomes, we found that prosocial behavior was negatively associated with aggression, deviant peer association, risky sexual behavior, substance use, and delinquency, as well as depression and general internalizing symptoms (e.g., emotional difficulties, negative emotionality). Differences in the strength of relations between prosocial behavior and externalizing behavior and internalizing symptoms, respectively, may be based on adolescents' self-regulatory capacities. That is, while engagement in prosocial behavior requires optimal levels of self-regulation, participation in externalizing behaviors is rooted in under-regulation; and experiences with internalizing symptoms can occur as a result of over-regulation (Jessor, 
1987; Jessor \& Jessor, 1977). It could be that prosocial behavior and externalizing behaviors are especially incongruous because a person who is regulated in one sense (i.e., helpful) is unlikely to be poorly regulated in terms of other behaviors (i.e., externalizing behavior); whereas a person who is regulated in their helping behavior might also be (over) regulated in terms of internalizing symptoms. Thus, individuals may be able to simultaneously engage in prosocial behavior and experience internalizing symptoms, whereas prosocial and externalizing behavior might be less compatible. Future research should seek to test empirically and validate this explanation in order to clarify why higher levels of prosocial behavior are more strongly related to lower levels of externalizing behaviors than to internalizing symptoms. Pursuing this line of research will provide clarity to researchers, along with additional justification for studying relations between prosocial behavior and problematic outcomes from a resilience framework.

\subsection{Moderating factors}

This meta-analysis sought to better understand factors that strengthened or weakened associations between prosocial behavior and problematic outcomes. Low statistical power inhibited our ability to find and meaningfully interpret significant moderators that could conceptually explain heterogeneity in these associations. We urge researchers to regularly report participants' demographic information in future studies, and to assess whether individuals' demographic traits and characteristics are related to the association between prosocial behavior and problematic outcomes. Doing so will help individuals who are concerned with adolescents' positive development and health to better understand the unique lived experiences of diverse and disadvantaged youth, particularly in terms of the relation between their helpfulness and problematic outcomes.

One moderator finding, however, was noteworthy for the field at this time: the way prosocial behavior is measured (or labeled) is relevant to the strength of the association between prosocial behavior and problematic outcomes. More specifically, moderator analyses revealed the link between helping behavior and externalizing behavior was strongest when helping behavior was operationalized as prosocial behavior $(r+=.23)$, which was independent of other types of helping behavior that were considered. This association was next strongest when multiple measures of helping behavior were assessed within one study $(r+=.20)$. Associations were weaker when operationalized as altruism $(r+=.18)$ and volunteering/community service $(r+=.12)$. This pattern of findings seems to suggest that global measures of helping behavior (i.e., prosocial behavior) yield stronger associations with externalizing behaviors than more narrowly defined types of helping behaviors (e.g., volunteering/community service). It is possible that this is because general measures capture more variance in helping behavior than narrowly defined measures. However, these findings should be interpreted and applied with caution, based on past work that highlights the multidimensional nature of prosocial behavior (e.g., types, targets; Carlo et al., 2003; Padilla Walker \& Carlo, 2014). Therefore, researchers should be increasingly aware and purposeful when choosing measures of helping behavior to include in future studies in order to focus on the type that best suits their research questions and interests.

\subsection{Directions for future research}

Few extant studies analyzed associations between prosocial behavior and hyperactivity, risky sexual behavior, low self-esteem, and suicide ideation, respectively. However, these problematic outcomes are concerning to parents, teachers, and researchers because they have similarly negative (though distinct) effects on adolescents' development as more commonly studied problematic outcomes (e.g., Bardone et al., 1998; Lasgaard, Goossens, \& Elklit, 2011; Woodward \& Fergusson, 2001). As such, researchers should seriously consider investigating associations between prosocial behaviors and these constructs, in order to expand the prosocial literature by integrating it with theories of resilience.

Additionally, we found weak evidence that associations between prosocial and externalizing behaviors were stronger when measured longitudinally rather than cross-sectionally, suggesting these associations may strengthen over time. Still, our study was hampered in its ability to deduce the directionality of these associations. Some research shows engagement in prosocial behavior decreases the amount of problematic outcomes youth participate in or experience over time (e.g., Padilla-Walker et al., 2015b; 2017), while other research suggests that involvement in problem behaviors can reduce prosocial behaviors over time (Carlo, Allen, \& Buhman, 1999; Kosterman et al., 2011; Wentzel \& McNamara, 1999). Clarifying the directionality of associations between prosocial behaviors and problem behaviors across adolescence is a priority for future research.

Also, we were unable to assess whether "reporter" (i.e., self, peer, teacher, parent, observer, interviewer) acted as a moderator in associations between prosocial behavior and problematic outcomes, due to the variability in who reported on these constructs within and across studies. However, self-report formats were used at least in some part in 36 of the 55 included studies. Given concerns regarding self-presentation bias (and shared method variance associated with the use of more than one self-report instrument in a study), future researchers should aim to assess relations between prosocial behavior and problematic outcomes using multiple reporters within the same study.

Relatedly, existing psychological assessments of prosocial behavior most often assess individuals' perceptions of themselves as prosocial beings, rather than capture enacted prosocial behavioral frequencies. Accordingly, the interpretation of relations between prosocial behavior and problematic outcomes across studies should be interpreted cautiously. Scholars should prioritize the development of prosocial assessments that tap actual behavioral frequencies of respondents, as well as the investigation of how individuals' frequencies of prosocial behavior relate to problematic outcomes. 


\section{References}

Allen, J. P., McElhaney, K. B., Land, D. J., Kuperminc, G. P., Moore, C. W., O'Beirne-Kelly, H., et al. (2003). A secure base in adolescence: Markers of attachment security in the mother-adolescent relationship. Child Development, 74(1), 292-307. https://doi.org/10.1111/1467-8624.t01-1-00536.

Allen, J. P., Philliber, S., Herrling, S., \& Kuperminc, G. P. (1997). Preventing teen pregnancy and academic failure: Experimental evaluation of a developmentally based approach. Child Development, 68(4), 729-742. https://doi.org/10.2307/1132122.

American Psychiatric Association (2013). Diagnostic and statistical manual of mental disorders (DSM-5 ${ }^{\circledast}$ ). Arlington, VA: American Psychiatric Pub.

Aquino, K., \& Reed, A., II (2002). The self-importance of moral identity. Journal of Personality and Social Psychology, 83(6), 1423-1440. https://doi.org/10.1037/00223514.83.6.1423.

Arnett, J. J. (2000). Emerging adulthood: A theory of development from the late teens through the twenties. American Psychologist, 55(5), 469-480. https://doi.org/10. 1037//0003-066X.55.5.469.

Babinski, L. M., Hartsough, C. S., \& Lambert, N. M. (1999). Childhood conduct problems, hyperactivity-impulsivity, and inattention as predictors of adult criminal activity. The Journal of Child Psychology and Psychiatry and Allied Disciplines, 40(3), 347-355. https://doi.org/10.1111/1469-7610.00452.

Bandura, A., Pastorelli, C., Barbaranelli, C., \& Caprara, G. V. (1999). Self-efficacy pathways to childhood depression. Journal of Personality and Social Psychology, 76, 258-269.

Bardone, A. M., Moffitt, T. E., Caspi, A., Dickson, N., Stanton, W. R., \& Silva, P. A. (1998). Adult physical health outcomes of adolescent girls with conduct disorder, depression, and anxiety. Journal of the American Academy of Child \& Adolescent Psychiatry, 37(6), 594-601. https://doi.org/10.1097/00004583-199806000-00009.

Berger, C., Batanova, M., \& Cance, J. (2015). Aggressive and prosocial? Examining latent profiles of behavior, social status, machiavellianism, and empathy. Journal of Youth and Adolescence, 44(12), 2230-2244. https://doi.org/10.1007/s10964-015-0298-9 Chen et al.,2000.

Biglan, A., Metzler, C., Wirt, R., Ary, D., Noel, J., Ochs, L., et al. (1990). Social and behavioral factors associated with high-risk sexual behavior among adolescents. Journal of Behavioral Medicine, 3, 245-261. https://doi.org/10.1007/BF00846833.

Blomberg, N. (2003). Effective discipline for misbehavior: In-school versus out-of-school suspension. Conceptos, $27,1-11$.

Blum, R. W. (2003). Positive youth development: A strategy for improving health. In F. Jacobs, D. Wertlieb, \& R. M. Lerner (Eds.). Handbook of applied developmental science: Vol. 2. Promoting positive child, adolescent, and family development through research, policies, and programs (pp. 237-252). Thousand Oaks, CA: Sage.

Borenstein, M., Hedges, L. V., Higgins, J. P., \& Rothstein, H. R. (2011). Introduction to meta-analysis. West Sussex, United Kingdom: John Wiley \& Sons, Ltd.

Carlo, G., Allen, J. B., \& Buhman, D. C. (1999). Facilitating and disinhibiting prosocial behaviors: The nonlinear interaction of trait perspective taking and trait personal distress on volunteering. Basic and Applied Social Psychology, 21(3), 189-197. https://doi.org/10.1207/15324839951036362.

Carlo, G., Crockett, L. J., Wilkinson, J. L., \& Beal, S. J. (2011). The longitudinal relationships between rural adolescents' prosocial behaviors and young adult substance use. Journal of Youth and Adolescence, 4(9), 1192-1202. https://doi.org/10.1007/s10964-010-9588-4.

Carlo, G., Hausmann, A., Christiansen, S., \& Randall, B. A. (2003). Sociocognitive and behavioral correlates of a measure of prosocial tendencies for adolescents. The Journal of Early Adolescence, 23(1), 107-134. https://doi.org/10.1177/0272431602239132.

Carlo, G., Mestre, M. V., McGinley, M. M., Tur-Porcar, A., Samper, P., \& Opal, D. (2014). The protective role of prosocial behaviors on antisocial behaviors: The mediating effects of deviant peer affiliation. Journal of Adolescence, 37(4), 359-366. https://doi.org/10.1016/j.adolescence.2014.02.009.

Carter, A. (2019). The consequences of adolescent delinquent behavior for adult employment outcomes. Journal of Youth and Adolescence, 48(1), 17-29. https://doi. org/10.1007/s10964-018-0934-2.

Chen, X., Li, D., Li, Z., Li, B., \& Liu, M. (2000). Sociable and prosocial dimensions of social competence in Chinese children: Common and unique contributions to social, academic, and psychological adjustment. Developmental Psychology, 36(6), 302-314. https://doi.org/10.1037/0012-1649.36.3.302.

Ciocanel, O., Power, K., Eriksen, A., \& Gillings, K. (2016). Effectiveness of positive youth development interventions: A meta-analysis of randomized controlled trials. Journal of Youth and Adolescence, 45(8), 1-22. https://doi.org/10.1007/s10964-016-0555-6.

Cole, P. M., Zahn-Waxler, C., Fox, N. A., Usher, B. A., \& Welsh, J. D. (1996). Individual differences in emotion regulation and behavior problems in preschool children. Journal of Abnormal Psychology, 105, 518-529. https://doi.org/10.1037/0021-843X.105.4.518.

Coyne, S. M., Nelson, D. A., \& Underwood, M. (2010). Aggression in children. In P. K. Smith, \& C. H. Hart (Eds.). The Wiley-Blackwell handbook of childhood social development (pp. 491-509). Hoboken, New Jersey: Wiley. https://doi.org/10.1002/9781444390933.ch26.

Davis, A., Carlo, G., Schwartz, S., Unger, J., Zamboanga, B., Lorenzo-Blanco, E., ... Soto, D. (2016). The longitudinal associations between discrimination, depressive symptoms, and prosocial behaviors in U.S. Latino/a recent immigrant adolescents. Journal of Youth and Adolescence, 45(3), 457-470. https://doi.org/10.1007/ s10964-015-0394-X.

Davis, A. N., Carlo, G., Hardy, S. A., Olthuis, J. V., \& Zamboanga, B. L. (2017). Bidirectional relations between different forms of prosocial behaviors and substance use among female college student athletes. The Journal of Social Psychology, 157, 2017(6), 645-657. https://doi.org/10.1080/00224545.2016.1263596.

Department for Communities and Local Government (2010). Citizenship survey: 2009-10 (April 2009 - March 2010), England. London, UK: UK Government.

Doljanac, R. F., \& Zimmerman, M. A. (1998). Psychosocial factors and high-risk sexual behavior: Race differences among urban adolescents. Journal of Behavioral Medicine, 21(5), 451-467. https://doi.org/10.1023/A:1018784326191.

Duncan, S. C., Duncan, T. E., Strycker, L. A., \& Chaumeton, N. R. (2002). Relations between youth antisocial and prosocial activities. Journal of Behavioral Medicine, 25(5), 425-438. https://doi.org/10.1023/A:1020466906928.

Duval, S., \& Tweedie, R. (2000). Trim and fill: A simple funnel-plot-based method of testing and adjusting for publication bias in meta-analysis. Biometrics, 56(2), $455-463$.

Eberly, M. B., \& Montemayor, R. (1998). Doing good deeds: An examination of adolescent prosocial behavior in the context of parent-adolescent relationships. Journal of Adolescent Research, 13(4), 403-432. https://doi.org/10.1177/0743554898134003.

Eccles, J. S., \& Barber, B. L. (1999). Student council, volunteering, basketball, or marching band: What kind of extracurricular involvement matters? Journal of Adolescent Research, 14(1), 10-43. https://doi.org/10.1177/0743558499141003.

Eisenberg, N., Fabes, R. A., Karbon, M., Murphy, B. C., Wosinski, M., Polazzi, L., \& Juhnke, C. (1996). The relations of children's dispositional prosocial behavior to emotionality, regulation, and social functioning. Child Development, 67, 974-992. https://www.jstor.org/stable/1131874.

Eisenberg, N., Guthrie, I. K., Murphy, B. C., Shepard, S. A., Cumberland, A., \& Carlo, G. (1999). Consistency and development of prosocial dispositions: A longitudinal study. Child Development, 70, 1360-1372.

Eisenberg, N., Miller, P. A., Shell, R., McNalley, S., \& Shea, C. (1991). Prosocial development in adolescence: A longitudinal study. Developmental Psychology, 27(5), 849-857.

Eisenberg, N., Spinrad, T. L., \& Knafo-Noam, A. (2015). Prosocial development. In M. Lamb, C. Garcia-Coll, R. M. Lerner, \& Vol (Eds.). Handbook of child psychology (7thed.)New York: Wiley. https://doi.org/10.1002/9781118963418.childpsy315.

Flouri, E., \& Sarmadi, Z. (2016). Prosocial behavior and childhood trajectories of internalizing and externalizing problems: The role of neighborhood and school contexts. Developmental Psychology, 52(2), 253-258. https://doi.org/10.1037/dev0000076.

Flynn, E., Ehrenreich, S. E., Beron, K. J., \& Underwood, M. K. (2015). Prosocial behavior: Long-term trajectories and psychosocial outcomes. Social Development, 24(3), 462-482. https://doi.org/10.1111/sode.12100.

Fujiwara, T. (2009). Is altruistic behavior associated with major depression onset? PloS One, 4(2), 1-6. https://doi.org/10.1371/journal.pone.0004557.

Gerardy, H., Mounts, N. S., Luckner, A. E., \& Valentiner, D. P. (2015). Mothers' management of adolescent peer relationships: Associations with aggressive, prosocial, and playful behavior. The Journal of Genetic Psychology: Research and Theory on Human Development, 176(5), 299-314. https://doi.org/10.1080/00221325.2015. 1066746.

Gilchrist, L. D. (2017). Social competence in adolescence. In S. P. Schinke, J. K. Whittaker, \& S. Briar (Eds.). Behavioral methods in social welfare (pp. 61-80). Aldine, NY: Routledge.

Gill, K. L., \& Calkins, S. D. (2003). Do aggressive/destructive toddlers lack concern for others? Behavioral and physiological indicators of empathic responding in 2year-old children. Development and Psychopathology, 15(1), 55-71. https://doi.org/10.1017/S095457940300004X. 
Gremmen, M. C., Berger, C., Ryan, A. M., Steglich, C. E., Veenstra, R., \& Dijkstra, J. K. (2018). Adolescents' friendships, academic achievement, and risk behaviors: Same-behavior and cross-behavior selection and influence processes. Child Development, 90(2), e192-e211. https://doi.org/10.1111/cdev.13045.

Groeben, M., Perren, S., Stadelmann, S., \& von Klitzing, K. (2011). Emotional symptoms from kindergarten to middle childhood: Associations with self-and otheroriented social skills. European Child \& Adolescent Psychiatry, 20(1), 3-15. https://doi.org/10.1007/s00787-010-0139-Z

Guimond, F. A., Laursen, B., Hartl, A. C., \& Cillessen, A. H. (2018). Differences in internalizing symptoms anticipate adolescent friendship dissolution. Journal of Research on Adolescence, 29(4), 924-937. https://doi.org/10.1111/jora.12432.

Hardy, S. A., Dollahite, D. C., Johnson, N., \& Christensen, J. B. (2015). Adolescent motivations to engage in pro-social behaviors and abstain from health-risk behaviors: A self-determination theory approach. Journal of Personality, 83(5), 479-490. https://doi.org/10.1111/jopy.12123.

Haroz, E. E., Murray, L. K., Bolton, P., Betancourt, T., \& Bass, J. K. (2013). Adolescent resilience in Northern Uganda: The role of social support and prosocial behavior in reducing mental health problems. Journal of Research on Adolescence, 23(1), 138-148. https://doi.org/10.1111/j.1532-7795.2012.00802.x.

Hart, D., Atkins, R., \& Ford, D. (1998). Urban America as a context for development of moral identity in adolescence. Journal of Social Issues, 54(3), 513-530. https:// doi.org/10.1111/0022-4537.801998080.

Hatta, M. O., De Mol, J., Maurage, P., \& Gabriel, B. (2018). Effet médiateur des comportements prosociaux entre difficultés psychologiques et consommation de substances psychoactives chez des adolescents togolais. Alcoologie et addictologie, 40(2), 131-139.

Hawley, P. H. (2003). Prosocial and coercive configurations of resource control in early adolescence: A case for the well-adapted machiavellian. Merrill-Palmer Quarterly, 49(3), 279-309. https://doi.org/10.1353/mpq.2003.0013.

Hawley, P. H. (2014). Evolution, prosocial behavior, and altruism. In L. M. Padilla-Walker, \& G. Carlo (Eds.). Prosocial development: A multidimensional approach (pp. 43-69). New York, NY: Oxford University Press.

Hay, D. F., Hudson, K., \& Liang, W. (2010). Links between preschool children's prosocial skills and aggressive conduct problems: The contribution of ADHD symptoms. Early Childhood Research Quarterly, 25, 493-501. https://doi.org/10.1016/j.ecresq.2010.01.003.

Hay, D. F., \& Pawlby, S. (2003). Prosocial development in relation to children's and mothers' psychological problems. Child Development, 74(5), 1314-1327.

Hymel, S., Rubin, K. H., Rowden, L., \& LeMare, L. (1990). Children's peer relationships: Longitudinal prediction of internalizing and externalizing problems from middle to late childhood. Child Development, 61(6), 2004-2021.

Intravia, J., Pelletier, E., Wolff, K. T., \& Baglivio, M. T. (2017). Community disadvantage, prosocial bonds, and juvenile reoffending: A multilevel mediation analysis. Youth Violence and Juvenile Justice, 15(3), 240-263. https://doi.org/10.1177/1541204016639350.

Jenkinson, C. E., Dickens, A. P., Jones, K., Thompson-Coon, J., Taylor, R. S., Rogers, M., ... Richards, S. H. (2013). Is volunteering a public health intervention? A systematic review and meta-analysis of the health and survival of volunteers. BMC Public Health, 13(1), 1-10. https://doi.org/10.1186/1471-2458-13-773.

Jessor, R. (1987). Problem-behavior theory, psychosocial development, and adolescent problem drinking. British Journal of Addiction, 82(4), 331-342.

Jessor, R., \& Jessor, S. L. (1977). Problem behavior and psychosocial development: A longitudinal study of youth. San Diego, CA: Academic Press.

Jie, Z., Norvilitis, J. M., \& Ingersoll, T. S. (2007). Idiocentrism, allocentrism, psychological well being and suicidal ideation: A cross cultural study. Omega. Journal Of Death \& Dying, 55(2), 131-144. https://doi.org/10.2190/OM.55.2.c Kauffman et al., 2007.

Kalff, A. C., Kroes, M., Vles, J. S. H., Bosma, H., Feron, F. J. M., Hendriksen, J. G. M., ... Jolles, J. (2001). Factors affecting the relation between parental education as well as occupation and problem behaviour in Dutch 5-to 6-year-old children. Social Psychiatry and Psychiatric Epidemiology, 36(7), 324-331. https://doi.org/10. $1007 / \mathrm{s} 001270170036$.

Kaplan, H. B., Johnson, R. J., \& Bailey, C. A. (1987). Deviant peers and deviant behavior: Further elaboration of a model. Social Psychology Quarterly, 50(3), 277-284. https://www.jstor.org/stable/2786829.

Kaufmann, D. R., Wyman, P. A., Forbes-Jones, E., \& Barry, J. (2007). Prosocial involvement and antisocial peer affiliations as predictors of behavior problems in urban adolescents: Main effects and moderating effects. Journal of Community Psychology, 35(4), 417-434. https://doi.org/10.1002/jcop.20156.

Kokko, K., Tremblay, R. E., Lacourse, E., Nagin, D. S., \& Vitaro, F. (2006). Trajectories of prosocial behavior and physical aggression in middle childhood: Links to adolescent school dropout and physical violence. Journal of Research on Adolescence, 16(3), 403-428. https://doi.org/10.1111/j.1532-7795.2006.00500.x.

Kosterman, R., Hawkins, J. D., Abbott, R. D., Hill, K. G., Herrenkohl, T. I., \& Catalano, R. F. (2005). Measures of positive adult behavior and their relationship to crime and substance use. Prevention Science, 6(1), 21-33. https://doi.org/10.1007/s11121-005-1250-0.

Kosterman, R., Mason, W. A., Haggerty, K. P., Hawkins, J. D., Spoth, R., \& Redmond, C. (2011). Positive childhood experiences and positive adult functioning: Prosocial continuity and the role of adolescent substance use. Journal of Adolescent Health, 49(2), 180-186. https://doi.org/10.1016/j.jadohealth.2010.11.244.

Krueger, R. F., Hicks, B. M., \& McGue, M. (2001). Altruism and antisocial behavior: Independent tendencies, unique personality correlates, distinct etiologies. Psychological Science, 12(5), 397-402. https://doi.org/10.1111/1467-9280.00373.

Lacourse, E., Nagin, D. S., Vitaro, F., Côté, S., Arseneault, L., \& Tremblay, R. E. (2006). Prediction of early-onset deviant peer group affiliation: A 12-year longitudinal study. Archives of General Psychiatry, 63(5), 562-568. https://doi.org/10.1001/archpsyc.63.5.562.

Laible, D., McGinley, M., Carlo, G., Augstine, M., \& Murphy, T. (2014). Does engaging in prosocial behavior make children see the world through rose-colored glasses? Developmental Psychology, 50(3), 872-880. https://doi.org/10.1037/a0033905.

Lasgaard, M., Goossens, L., \& Elklit, A. (2011). Loneliness, depressive symptomatology, and suicide ideation in adolescence: Cross-sectional and longitudinal analyses. Journal of Abnormal Child Psychology, 39(1), 137-150. https://doi.org/10.1007/s10802-010-9442-x.

Leadbeater, B. J., Kuperminc, G. P., Blatt, S. J., \& Hertzog, C. (1999). A multivariate model of gender differences in adolescents' internalizing and externalizing problems. Developmental Psychology, 35(5), 1268-1282. https://doi.org/10.1037/0012-1649.35.5.1268.

Lederer, A. M., Autry, D. M., Day, C. R. T., \& Oswalt, S. B. (2015). The impact of work and volunteer hours on the health of undergraduate students. Journal of American College Health, 63(6), 403-408. https://doi.org/10.1080/07448481.2015.1015028.

Lee, M. T., Pagano, M. E., Johnson, B. R., Post, S. G., Leibowitz, G. S., \& Dudash, M. (2017). From defiance to reliance: Spiritual virtue as a pathway towards desistence, humility, and recovery among juvenile offenders. Spirituality in Clinical Practice, 4(3), 161-175. https://doi.org/10.1037/scp0000144.

Lerner, R. M., Lerner, J. V., Bowers, E., \& Geldhof, G. J. (2015). Positive youth development and relational developmental systems. In W. F. Overton, \& P. C. Molenaar (Eds.). Theory and method. Volume 1 of the handbook of child psychology and developmental science (pp. 607-651). (7th ed.). Hoboken, NJ: Wiley. https://doi.org/10. 1002/9781118963418.childpsy116.

Lipsey, M. W., \& Wilson, D. B. (2001). Practical meta-analysis. Thousand Oaks, CA: Sage.

Masten, A. S. (2001). Ordinary magic: Resilience processes in development. American Psychologist, 56(3), 227-238. https://doi.org/10.1037//0003-066X.56.3.227.

Masten, A. S., \& Cicchetti, D. (2010). Developmental cascades. Development and Psychopathology, 22(3), 491-495. https://doi.org/10.1017/S0954579410000222.

Masten, C. L., Eisenberger, N. I., Borofsky, L. A., Pfeifer, J. H., McNealy, K., Mazziotta, J. C., et al. (2009). Neural correlates of social exclusion during adolescence: Understanding the distress of peer rejection. Social Cognitive and Affective Neuroscience, 4(2), 143-157. https://doi.org/10.1093/scan/nsp007.

McDade, R. S., King, K. A., Vidourek, R. A., \& Merianos, A. L. (2018). Impact of prosocial behavioral involvement on school violence perpetration among African American middle school and high school students. Journal of Immigrant and Minority Health, 20(1), 7-13. https://doi.org/10.1007/s10903-016-0544-6.

McGinley, M., \& Carlo, G. (2007). Two sides of the same coin? The relations between prosocial and physically aggressive behaviors. Journal of Youth and Adolescence, 36(3), 337-349. https://doi.org/10.1007/s10964-006-9095-9.

McLaughlin, K. A., Hatzenbuehler, M. L., \& Hilt, L. M. (2009). Emotion dysregulation as a mechanism linking peer victimization to internalizing symptoms in adolescents. Journal of Consulting and Clinical Psychology, 77(5), 894-904. https://doi.org/10.1037/a0015760.

McLoyd, V. C. (1997). The impact of poverty and low socioeconomic status on the socioemotional functioning of African-American children and adolescents Mediating effects. In R. D. Taylor, \& M. C. Wang (Eds.). Social and emotional adjustment and family relations in ethnic minority families (pp. 7-34). New York, NY: Routledge.

Mestre, A. L., Mesurado, B., \& García, P. S. (2014). El rol mediador de la empatía, la conducta prosocial y la conducta agresiva en la depresion y la ansiedad. Ansiedad y Estres, 20(2-3), 247-258.

Nantel-Vivier, A., Pihl, R. O., Côté, S., \& Tremblay, R. E. (2014). Developmental association of prosocial behaviour with aggression, anxiety and depression from infancy to preadolescence. Journal of Child Psychology and Psychiatry, 55(10), 1135-1144. https://doi.org/10.1111/jcpp.12235. 
Nielson, M. G., Padilla-Walker, L., \& Holmes, E. K. (2017). How do men and women help? Validation of a multidimensional measure of prosocial behavior. Journal of Adolescence, 56, 91-106. https://doi.org/10.1016/j.adolescence.2017.02.006.

Padilla Walker, L. M., \& Carlo, G. (2014). The study of prosocial behavior. In L. M. Walker, \& G. Carlo (Eds.). Prosocial development: A multidimensional approach (pp. $3-$ 17). New York, NY: Oxford University Press.

Padilla-Walker, L. M., Memmott-Elison, M. K., \& Coyne, S. M. (2017). Associations between prosocial and problem behavior from early to late adolescence. Journal of Youth and Adolescence, 47(5), 961-975. https://doi.org/10.1007/s10964-017-0736-y.

Padilla-Walker, L. M., Memmott-Elison, M. K., \& Coyne, S. M. (2018). Associations between prosocial and problem behavior from early to late adolescence. Journal of Youth and Adolescence, 47(5), 961-975. https://doi.org/10.1007/s10964-017-0736-y.

Padilla Walker, L. M., Carlo, G., \& Nielson, M. G. (2015b). Does helping keep teens protected? Longitudinal bidirectional relations between prosocial behavior and problem behavior. Child Development, 86(6), 1759-1772. https://doi.org/10.1111/cdev.12411.

Padilla Walker, L. M., Dyer, W. J., Yorgason, J. B., Fraser, A. M., \& Coyne, S. M. (2015a). Adolescents' prosocial behavior toward family, friends, and strangers: A person-centered approach. Journal of Research on Adolescence, 25(1), 135-150. https://doi.org/10.1111/jora.12102.

Perren, S., Forrester-Knauss, C., \& Alsaker, F. D. (2012). Self and other-oriented social skills: Differential associations with children's mental health and bullying roles. Journal for Educational Research Online, 4, 99-123.

Perren, S., Stadelmann, S., von Wyl, A., \& von Klitzing, K. (2007). Pathways of behavioural and emotional symptoms in kindergarten children: What is the role of prosocial behaviour? European Child \& Adolescent Psychiatry, 16, 209-214. https://doi.org/10.1007/s00787-006-0588-6.

Persson, G. E. B. (2005). Developmental perspectives on prosocial and aggressive motives in preschoolers' peer interactions. International Journal of Behavioral Development, 29, 80-91. https://doi.org/10.1080/01650250444000423.

Piff, P. K., Kraus, M. W., Côté, S., Cheng, B. H., \& Keltner, D. (2010). Having less, giving more: The influence of social class on prosocial behavior. Journal of Personality and Social Psychology, 99(5), 771-784. https://doi.org/10.1037/a0020092.

Pursell, G. R., Laursen, B., Rubin, K. H., Booth-LaForce, C., \& Rose-Krasnor, L. (2008). Gender differences in patterns of association between prosocial behavior, personality, and externalizing problems. Journal of Research in Personality, 42(2), 472-481. https://doi.org/10.1016/j.jrp.2007.06.003.

Ranney, J. D. (2016). Popular in the digital age: Self-monitoring, aggression, and prosocial behaviors in digital contexts and their associations with popularity (Unpublished doctoral dissertation)Fargo, North Dakota: North Dakota State University.

van Rijsewijk, L., Dijkstra, J. K., Pattiselanno, K., Steglich, C., \& Veenstra, R. (2016). Who helps whom? Investigating the development of adolescent prosocial relationships. Developmental Psychology, 52(6), 894-908. https://doi.org/10.1037/dev0000106.

Rubin, K. H., Coplan, R. J., \& Bowker, J. C. (2009). Social withdrawal in childhood. Annual Review of Psychology, 60, 141-171. https://doi.org/10.1146/annurev. psych.60.110707.163642.

Schacter, H. L., \& Margolin, G. (2018). When it feels good to give: Depressive symptoms, daily prosocial behavior, and adolescent mood. Emotion, 19(5), 923-927. https://doi.org/10.1037/emo0000494.

Silver, N. C., \& Dunlap, W. P. (1987). Averaging correlation coefficients: Should Fisher's z transformation be used? Journal of Applied Psychology, 72(1), 146-148. https://doi.org/10.1037/0021-9010.72.1.146.

Steinberg, L. (2007). Risk taking in adolescence: New perspectives from brain and behavioral science. Current Directions in Psychological Science, 16(2), 55-59. https:// doi.org/10.1111/j.1467-8721.2007.00475.x.

Taylor, P. J., \& Wood, A. M. (2013). Discrepancies in parental and self-appraisals of prosocial characteristics predict emotional problems in adolescents. British Journal of Clinical Psychology, 52(3), 269-284. https://doi.org/10.1111/bjc.12013.

Telzer, E. H., Tsai, K. M., Gonzales, N., \& Fuligni, A. J. (2015). Mexican American adolescents' family obligation values and behaviors: Links to internalizing symptoms across time and context. Developmental Psychology, 51(1), 75-86. https://doi.org/10.1037/a0038434.

Uggen, C., \& Janikula, J. (1999). Volunteerism and arrest in the transition to adulthood. Social Forces, 78(1), 331-363.

Wang, M., \& Saudino, K. J. (2015). Positive affect: Phenotypic and etiologic associations with prosocial behaviors and internalizing problems in toddlers. Frontiers in Psychology, 6, 416. https://doi.org/10.3389/fpsyg.2015.00416.

Wentzel, K. R., \& McNamara, C. C. (1999). Interpersonal relationships, emotional distress, and prosocial behavior in middle school. The Journal of Early Adolescence, 19(1), 114-125. https://doi.org/10.1177/0272431699019001006.

Williams, L. R., Degnan, K. A., Perez-Edgar, K. E., Henderson, H. A., Rubin, K. H., Pine, D. S., ... Fox, N. A. (2009). Impact of behavioral inhibition and parenting style on internalizing and externalizing problems from early childhood through adolescence. Journal of Abnormal Child Psychology, 37(8), 1063-1075. https://doi.org/ 10.1007/s10802-009-9331-3.

Woodward, L. J., \& Fergusson, D. M. (2001). Life course outcomes of young people with anxiety disorders in adolescence. Journal of the American Academy of Child \& Adolescent Psychiatry, 40(9), 1086-1093. https://doi.org/10.1097/00004583-200109000-00018.

Wright, B. C. (2015). Altruism and depression: Exploring this relationship and the mechanisms behind it (Unpublished doctoral dissertation)United States of America: University of North Texas, Texas.

Zimmer-Gembeck, M. J., Geiger, T. C., \& Crick, N. R. (2005). Relational and physical aggression, prosocial behavior, and peer relations: Gender moderation and bidirectional associations. The Journal of Early Adolescence, 25(4), 421-452. https://doi.org/10.1177/02724316052798.

Zimmer-Gembeck, M. J., Hunter, T. A., \& Pronk, R. (2007). A model of behaviors, peer relations and depression: Perceived social acceptance as a mediator and the divergence of perceptions. Journal of Social and Clinical Psychology, 26, 273-302. 